\title{
2. SYNOPSIS
}

\begin{tabular}{|c|c|c|}
\hline $\begin{array}{l}\text { Name of Company: } \\
\text { I.R.I.S. } \\
\text { 50 rue Carnot } \\
\text { 92150 Suresnes - FRANCE } \\
\end{array}$ & $\begin{array}{lc}\text { Individual } & \text { Study } \\
\text { Referring } & \text { to } \\
\text { of the Dossier } & \end{array}$ & $\begin{array}{l}\text { (For National Authority Use } \\
\text { only) }\end{array}$ \\
\hline 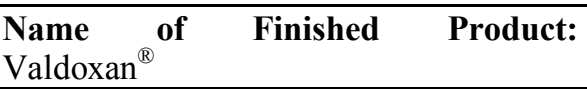 & Volume: & \\
\hline $\begin{array}{l}\text { Name of Active Ingredient: } \\
\text { Agomelatine (S 20098) }\end{array}$ & Page: & \\
\hline \multicolumn{3}{|c|}{$\begin{array}{l}\text { Title of study: } \\
\text { Evaluation of the effects of agomelatine }(25 \mathrm{mg} \text { and } 50 \mathrm{mg}) \text { and escitalopram } 20 \mathrm{mg} \text { during } 9 \text { weeks on } \\
\text { emotional blunting, emotional processing and motivation in healthy male and female volunteers. } \\
\text { A phase I, national, multicentric, randomised, double-blind, placebo-controlled study with } 4 \text { parallel groups. } \\
\text { Protocol No.: CL1-20098-081 - EudraCT number: } 2010-024570-19 \\
\text { The description of the study protocol given hereafter includes the modifications of the four substantial } \\
\text { amendments to the protocol. }\end{array}$} \\
\hline \multicolumn{3}{|l|}{ Coordinator: } \\
\hline \multicolumn{3}{|c|}{ Study centres: Two centres in United Kingdom: } \\
\hline \multicolumn{3}{|c|}{ 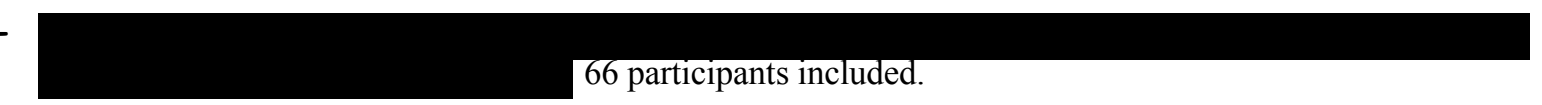 } \\
\hline \multicolumn{3}{|l|}{67 participants included. } \\
\hline \multicolumn{3}{|l|}{ reference): Not applicable. } \\
\hline $\begin{array}{l}\text { Studied period: } \\
\text { Initiation date: } 29 \text { December } 2011 . \\
\text { Completion date: } 25 \text { July } 2013 \text {. }\end{array}$ & & $\begin{array}{l}\text { Phase of development of the study: } \\
\text { Phase I }\end{array}$ \\
\hline \multicolumn{3}{|c|}{$\begin{array}{l}\text { Objectives: } \\
\text { The objective of this exploratory study was to assess the effects of two doses of agomelatine ( } 25 \mathrm{mg} \text { or } 50 \mathrm{mg} \text { ) } \\
\text { and escitalopram }(20 \mathrm{mg}) \text { on emotional blunting, emotional processing and motivation during } 9 \text { weeks } \\
\text { treatment (as modified by Amendment No. } 2 \text { from "8 weeks treatment") in healthy male and female } \\
\text { volunteers. }\end{array}$} \\
\hline \multicolumn{3}{|c|}{ Methodology: } \\
\hline \multicolumn{3}{|c|}{$\begin{array}{l}\text { This was a phase I, multicentric ( } 2 \text { centres), national (United Kingdom), randomised, double-blind, } \\
\text { placebo-controlled, without therapeutic benefit, in healthy volunteers, with } 4 \text { parallel groups (i.e. agomelatine } \\
25 \mathrm{mg} \text {, agomelatine } 50 \mathrm{mg} \text {, escitalopram } 20 \mathrm{mg} \text {, and placebo). } \\
\text { Randomisation was balanced (non-adaptive), with stratification on gender and on centre. } \\
\text { This study was performed in strict accordance with Good Clinical Practice including the archiving of essential } \\
\text { documents. }\end{array}$} \\
\hline \multicolumn{3}{|c|}{$\begin{array}{l}\text { Number of participants: } \\
\text { Planned: In all } 128 \text { participants ( } 64 \text { males and } 64 \text { females), } 32 \text { per group ( } 16 \text { males and } 16 \text { females). } \\
\text { Included: } 133 \text { participants ( } 67 \text { males and } 66 \text { females), } 33 \text { in the agomelatine } 25 \mathrm{mg} \text { group, } 32 \text { in the } \\
\text { agomelatine } 50 \mathrm{mg} \text { group, } 36 \text { in the escitalopram } 20 \mathrm{mg} \text { group and } 32 \text { in the placebo group. }\end{array}$} \\
\hline \multicolumn{3}{|c|}{$\begin{array}{l}\text { Main criteria for inclusion: } \\
\text { Healthy male and female volunteers, aged between } 18 \text { and } 45 \text { years (both inclusive), non-smokers or } \\
\text { moderate smokers ( } \leq 10 \text { cigarettes per day) with ability and willingness to undergo neuropsychological and } \\
\text { motivation tests batteries and self-rating or clinician-rated questionnaires. All participants had to sign an } \\
\text { informed consent. }\end{array}$} \\
\hline \multicolumn{3}{|c|}{$\begin{array}{l}\text { Study drug: } \\
\text { Agomelatine } 25 \mathrm{mg} \text { and } 50 \mathrm{mg} \text { - oral route }-1 \text { capsule in the evening at around } 8.00 \mathrm{p.m} \text {. from D0 (W0) to } \\
\text { D63 (W9). } \\
\text { Batch No.: Agomelatine } 25 \mathrm{mg} \text { : L0037212, L0046514; Agomelatine } 50 \mathrm{mg} \text { : L0037213, L0046516 }\end{array}$} \\
\hline
\end{tabular}




\section{Reference product:}

- Escitalopram - $10 \mathrm{mg}$ or $20 \mathrm{mg}$ - oral route - 1 capsule in the evening at around 8.00 p.m. Participants received $10 \mathrm{mg}$ /day from D0 (W0) to D7 (W1), $20 \mathrm{mg} /$ day from D7 (W1) to D56 (W8), and $10 \mathrm{mg}$ /day from D56 (W8) to D63 (W9) (tapering period).

- Placebo - oral route - 1 capsule in the evening at around 8.00 p.m. from D0 (W0) to D63 (W9).

\section{Duration of treatment:}

- Selection period: 1-6 weeks without treatment (according to Amendment No. 3) between selection visit (ASSE) and inclusion visit D0 (W0).

- 9 weeks of double-blind treatment period (according to Amendment No. 2) from D0 (W0) to D63 (W9):

- Agomelatine $25 \mathrm{mg}$ for 9 weeks.

- Agomelatine $50 \mathrm{mg}$ for 9 weeks.

- Escitalopram 10 or $20 \mathrm{mg}$ : $10 \mathrm{mg}$ for the first week, $20 \mathrm{mg}$ for the following 7 weeks and $10 \mathrm{mg}$ for the tapering period.

- Placebo for 9 weeks.

- Follow-up period without study treatment: 5-7 days after the end of the tapering period or in case of study withdrawal.

Criteria for evaluation:

PHARMACODYNAMIC ANALYSES

No primary criterion had been defined for this exploratory study

\section{Criteria assessing the emotional blunting:}

Emotional blunting was assessed by using the Oxford Depression Questionnaire (ODQ) at inclusion D0 (W0) (baseline, before drug intake, only section 1 of the ODQ) and at different time points after drug intake (sections 1 and 2 of the ODQ): visits D14 (W2), D55 (W8), follow-up visit (DEND) and in case of withdrawal if the participant withdrew on or after D35 (W5).

The following criteria were considered: ODQ total score, individual ODQ sections score, individual ODQ items (sections 1 and 2) scores, and individual ODQ dimension score (General reduction (GR), Emotional detachment (ED), Positive reduction (PR) and not caring (NC), and GR +ED and PR + NC ODQ dimension scores.

Moreover, an ODQ-Visual analogue scale (ODQ-VAS) including 8 items and the Gold Standard question on the level of blunting were evaluated at the same visits, except for items 1, 2 and 3 of the ODQ-VAS, also evaluated at D0 (W0).

Criteria assessing the emotional processing (perception and memory for positive and negative emotional information):

Five neuropsychological tests were performed at different time points following drug intake: visits D7 (W1), D55 (W8) or in case of withdrawal if the participant withdrew on or after D35 (W5). The tests were performed in the following order:

- Facial expression recognition task (FERT).

- Emotional categorisation task (ECAT).

- Faces dot-probe task (FDOT).

- Emotional memory free recall task (EREC).

- Emotional memory forced recognition task (EMEM).

\section{Criteria assessing motivation:}

A gait task (with and without a cognitive task) and a motivation score (from 0 to 10) to evaluate the volunteers motivation state, were assessed at inclusion D0 (baseline, before drug intake) and at different time points after drug intake: D3 (W0), D7 (W1), D14 (W2), D35 (W5) and D56 (W8) or in case of withdrawal if the participant withdrew on or after D35 (W5). 
Criteria for evaluation: (Cont'd)

PHARMACODYNAMIC ANALYSES (Cont'd)

Moreover, three motivation tasks were performed at different time points following drug intake: visit D3 (W0), D14 (W2) and D56 (W8) or in case of withdrawal if the participant withdrew on or after D35 (W5).

The following criteria were assessed:

- Sensitivity to reward and punishment in a basic probabilistic learning task (Task 1).

- Sensitivity to reward and punishment in a complex probabilistic learning task (Task 2).

- Motivation and effort duration task.

Criteria assessing sexual acceptability:

Sexual acceptability was assessed by using the Psychotropic-Related Sexual Dysfunction Questionnaire (PRSexDQ) at inclusion D0 (W0) (baseline, before drug intake) and at different time points after drug intake: visits D14 (W2), D35 (W5), D55 (W8), at the follow-up visit (DEND) and in case of withdrawal if the participant withdrew on or after D35 (W5). PRSexDQ total score and individual PRSexDQ item scores were considered.

A VAS on sexual functioning satisfaction (SFS-VAS) was also completed at the same visits.

\section{Criteria for volunteers' subjective assessments:}

Hospital Anxiety Depression (HAD) sub-scores, State-Trait Anxiety Inventory (STAI)-State total score, mood VAS (6-item VAS) scores and Social Adaptation Self Evaluation Scale (SASS) total score were assessed at inclusion visit D0 (W0), D7 (W1), D55 (W8) or in case of withdrawal if the participant withdrew on or after D35 (W5).

\section{Criteria assessing cognitive and physical functioning:}

The Massachusetts General and Hospital Cognitive and Physical Functioning Questionnaire (MGH-CPFQ) total score and sub-scores were assessed at inclusion visit D0 (W0), D14 (W2), D35 (W5) and D56 (W8) or in case of withdrawal if the participant withdrew on or after D35 (W5).

\section{SAFETY ANALYSES}

Adverse events and vital signs (systolic and diastolic blood pressure, heart rate) during the whole study, body weight and Body Mass Index (BMI) at ASSE, D0 (W0) and follow-up visit, laboratory parameters (blood and urine biochemistry and haematology) at ASSE, D14 (W2), D35 (W5) and follow-up (DEND) were evaluated.

\section{OTHER ASSESSMENTS NOT SPECIFICALLY RELATED TO PHARMACODYNAMICS OR SAFETY} MEASUREMENTS

Serum and plasma Brain Derived Neurotrophic Factor (BDNF) and Vascular Endothelial Growth Factor (VEGF) were measured at selection (ASSE), D14 (W2) and D35 (W5).

\section{DRUG CONCENTRATIONS}

Saliva samples were collected during the treatment period in order to measure concentrations of agomelatine and escitalopram for compliance determination. Moreover saliva samples were collected at D34 (W5) for pharmacokinetic analysis.

Agomelatine and escitalopram concentration in saliva were analysed by a central laboratory by using previously validated methods. 


\section{Statistical methods: \\ PHARMACODYNAMIC ANALYSES}

In addition to descriptive statistics by treatment group (and some by gender) for each analytical approach of criteria on D0-D56 in the PPS, the following analyses were performed:

- Emotional blunting: initially, scores obtained from the ODQ-VAS and ODQ total score were compared between some treatment groups using a linear model studying treatment effect with centre and gender as covariates (fixed effect). However, considering that the criterion deviates from the normal distribution, a non-parametric analysis, based on Hodges-Lehmann's estimate and Mann-Whitney test, was used (complementary analyses).

- Emotional Processing: two separate analyses of variance (ANOVA) models were used to estimate treatment effects with terms for Visit (Day 7, Day 55) on each evaluated criteria. Other initial factors in the model included main effect of treatment (4 levels), site (2 levels) and gender (2 levels).

- Motivation (Tasks 1, 2 \& 3): analysis of variance models were used to estimate treatment effects. Other analyses were used to study the interaction and other potential factors influencing the evaluated parameters.

- Sexual acceptability: total score values at each visit were compared between some treatment groups, using a linear model studying treatment effect with centre, gender and baseline as covariates (fixed effect), overall and by gender. Estimate of the difference (standard error) between adjusted group means was provided with its $95 \%$ confidence interval and $p$-value.

Motivation score, Gait task, individual items scores of the PRSexDQ and Sexual Functioning Satisfaction-VAS score, STAI-STATE anxiety questionnaire, Hospital Anxiety Depression (HAD) Scale, MOOD VAS, Social Adaptation Self-Evaluation Scale (SASS) as well as Massachusetts General Hospital Cognitive and Physical Functioning Questionnaire (MGH-CPFQ) were presented using descriptive statistics in terms of values at each visit and changes from baseline to each post-baseline visit if applicable.

\section{SAFETY ANALYSES}

Description of adverse events (total and emergent), vital signs, and biology parameters were provided in the Safety Set.

\section{OTHER ASSESSMENTS NOT SPECIFICALLY RELATED TO PHARMACODYNAMICS OR SAFETY}

For BDNF and VEGF measurements, descriptive statistics were provided on the whole study period by treatment group in the Safety Set.

\section{PHARMACOKINETICS}

The individual saliva concentrations were fit to an existing population pharmacokinetic model which had been developed for agomelatine (). As agomelatine was measured in saliva and not in plasma, a known correlation between agomelatine plasma and saliva concentrations was used to back-calculate plasma concentrations from saliva concentrations, in order to derive individual plasma pharmacokinetic parameters. The following pharmacokinetic parameters were obtained: $\mathrm{AUC}_{24}, \mathrm{C}_{\max }, \mathrm{t}_{\max }$ and $\mathrm{t}_{1 / 2, \mathrm{z}}$.

Since no population pharmacokinetic model was available for escitalopram, the plasma PK parameters of escitalopram were not estimated.

SUMMARY - CONCLUSIONS

STUDY POPULATION AND OUTCOME:

\begin{tabular}{|c|c|c|c|c|c|}
\hline & $\begin{array}{c}\text { Agomelatine } \\
25 \mathrm{mg} \\
(\mathrm{N}=33) \\
\end{array}$ & $\begin{array}{c}\text { Agomelatine } \\
50 \mathbf{~ m g} \\
(\mathbf{N}=\mathbf{3 2}) \\
\end{array}$ & $\begin{array}{c}\text { Escitalopram } \\
20 \mathrm{mg} \\
(\mathbf{N}=\mathbf{3 6}) \\
\end{array}$ & $\begin{array}{l}\text { Placebo } \\
(\mathbf{N}=32)\end{array}$ & $\begin{array}{c}\text { All } \\
(\mathbf{N}=\mathbf{1 3 3})\end{array}$ \\
\hline Included (randomised) & 33 & 32 & 36 & 32 & 133 \\
\hline Withdrawn due to & $4(12.1)$ & - & 7 (19.4) & $2(6.3)$ & $13(9.8)$ \\
\hline adverse event & $2(6.1)$ & - & $2(5.6)$ & - & $4(3.0)$ \\
\hline protocol deviation & $1(3.0)$ & - & $4(11.1)$ & - & $5(3.8)$ \\
\hline non-medical reason & $1(3.0)$ & - & $1(2.8)$ & $2(6.3)$ & $4(3.0)$ \\
\hline Completed the D0-D56 period & $29(87.9)$ & $32(100.0)$ & $29(80.6)$ & $30(93.8)$ & $120(90.2)$ \\
\hline Per Protocol Set (PPS) & $32(97.0)$ & $32(100)$ & $32(88.9)$ & $32(100)$ & $128(96.2)$ \\
\hline Safety Set & 33 (100) & $32(100)$ & $36(100)$ & $32(100)$ & $133(100)$ \\
\hline PK Set & $31(93.3)$ & $32(100)$ & - & - & $63(47.4)$ \\
\hline
\end{tabular}

$\%$ : expressed as percentage of the participants from the Randomised Set 


\section{SUMMARY - CONCLUSIONS (Cont'd)}

STUDY POPULATION AND OUTCOME (Cont'd):

A total of 137 participants were selected, and 133 were included and randomly assigned to one of the 4 groups. Considering the rules for replacing participants during the study (i.e. in case a participant withdrew before D35 (W5), he/she was to be replaced by another participant), the distribution of randomised participants according to the treatment dispensed at inclusion was well balanced: 33 participants in the agomelatine $25 \mathrm{mg}$ group (including one participant replaced), 32 in the agomelatine $50 \mathrm{mg}$ group, 36 in the escitalopram $20 \mathrm{mg}$ group (including four participants replaced) and 32 in the placebo group.

Over the D0-D56 period, the rate of withdrawals was higher in the escitalopram group than in the others groups. This difference was mainly due to withdrawals resulting from protocol deviation, which were more frequent in the escitalopram group than in the other groups (see Table above). Finally the percentage of included and randomised participants who completed the study at D56 was $87.9 \%$ in the agomelatine $25 \mathrm{mg}$ group, $100 \%$ in the agomelatine $50 \mathrm{mg}$ group, $80.6 \%$ in the escitalopram $20 \mathrm{mg}$ group and $93.8 \%$ in the placebo group.

In the Randomised Set, participants were $23.3 \pm 4.3$ years old on average ranging from 18 to 42 years, half were female $(49.6 \%)$.

At baseline, treatments groups were comparable in term of verbal intelligence quotient, personality and trait anxiety with a mean National Adult Reading Test (NART) total score of $118.3 \pm 5.1$, Revised-Eysenck Personality Questionnaire (EPQR) Extraversion, Neuroticism, Psychoticism and Lie scores of 17.1 \pm 3.9, $5.5 \pm 4.0,5.6 \pm 3.4$ and 7.7 \pm 4.0 , respectively, and State-Trait Anxiety Inventory (STAI)-TRAIT total score of $30.3 \pm 5.2$, without relevant differences between groups.

Participants did not feel emotionally blunted on average (mean ODQ Section 1 score $=3.0 \pm 4.5$, median 1.0). There was no relevant difference between groups for ODQ Section 1 score.

The mean motivation score at baseline was $7.7 \pm 1.0$ (median 8.0), with no relevant difference between either group or between genders. Regarding gait tasks, mean walking times were: $15.6 \pm 1.8 \mathrm{~s}$ for usual pace, $18.0 \pm 3.9 \mathrm{~s}$ for usual pace with the cognitive task, $10.7 \pm 1.3 \mathrm{~s}$ for fast walking, and $12.2 \pm 1.7 \mathrm{~s}$ for fast walking with the cognitive task, with no relevant difference either between groups or between genders.

For sexual acceptability the analyzed population was defined as the subset of participants of the PPS with physical sexual activity at baseline and at least one post baseline visit and includes 110 participants (82.7\%). The mean PRSexDQ total score was $0.5 \pm 1.3$ at inclusion, and the mean sexual functioning VAS score was $88.4 \pm 11.1 \mathrm{~mm}$ (median $90.0 \mathrm{~mm}$ ), indicating that participants were largely satisfied with their sexual functioning.

Overall at baseline, participants did not present cognitive and physical impairment, with a mean MGH-CPFQ total score of $14.6 \pm 1.9$. The mean SASS score was $48.6 \pm 4.9$, corresponding to "normal" social adaptation/functioning.

Participants did not show any signs of depression (HAD depression score ranged from 0 to 6 , mean score $=0.9 \pm 1.3$ ) and had no anxiety at baseline (mean HAD anxiety score $=3.6 \pm 2.5$ and mean STAI STATE score $=27.4 \pm 6.1$ ).

Mood VAS showed that on average, participants felt happy, calm and alert, and did not feel sad, hostile or anxious.

No relevant differences were observed between treatment groups or between genders for sexual activity, cognitive and physical functioning and subjective scales.

In the Randomised Set, mean treatment exposure was $59.7 \pm 11.9$ days (median 63.0 days), and was shorter in the escitalopram $20 \mathrm{mg}$ group $(54.6 \pm 19.5$ days $)$ than in the others groups $(60.1 \pm 10.1$ days in the agomelatine $25 \mathrm{mg}$ group, $62.8 \pm 1.4$ days in the agomelatine $50 \mathrm{mg}$ group and $61.8 \pm 4.7$ days in the placebo group). This difference was due to the four participants of the escitalopram $20 \mathrm{mg}$ group withdrawn from the study at D3 (3 volunteers) and D7 (1 volunteer), not included in the Per Protocol Set and replaced. Mean global compliance was $98.8 \pm 2.8 \%$, with no relevant difference between treatment groups. 


\section{PHARMACODYNAMIC RESULTS:}

\section{Emotional blunting}

No statistically significant difference either between agomelatine $(25 \mathrm{mg}$ and $50 \mathrm{mg})$ and placebo or between agomelatine ( $25 \mathrm{mg}$ and $50 \mathrm{mg}$ ) and escitalopram or escitalopram versus placebo, was observed in the PPS for ODQ total score at any visit during the study.

As regards ODQ-VAS, in the PPS no relevant differences were observed either between baseline and D55, or between groups in overall population.

The gold standard question on the level of blunting showed that at the end of the treatment period (D55) in the PPS, $10.3 \%, 13.3 \%, 17.2 \%$ and $17.2 \%$ of participants, respectively in the agomelatine $25 \mathrm{mg}, 50 \mathrm{mg}$, escitalopram $20 \mathrm{mg}$ and placebo groups, felt mild or moderate emotional effect of the treatment.

\section{Emotional processing:}

- Facial Expression Recognition Task (FERT)

- D7: In overall population, results on target sensitivity indicated a decrease in facial expression recognition following agomelatine $25 \mathrm{mg}(\mathrm{p}=0.030)$ and $50 \mathrm{mg}(\mathrm{p}=0.064)$ in comparison with escitalopram $10 \mathrm{mg}$. Compared to placebo, escitalopram $10 \mathrm{mg}$ showed a tendency for higher misclassifications to happy faces $(\mathrm{p}=0.068)$ as well as a decreased response bias towards labeling faces as disgust $(p=0.027)$ and as surprise $(p=0.042)$. Compared to placebo, agomelatine $25 \mathrm{mg}$ presented a response bias towards labeling faces as happy (misclassifications: $p=0.022$; response bias $\mathrm{p}=0.015)$. Misclassifications and response bias were higher at the dose of agomelatine $25 \mathrm{mg}$ compared to escitalopram $10 \mathrm{mg}$ (respectively $\mathrm{p}=0.016$ and $\mathrm{p}=0.023$ ).

- D55: no significant treatment effects were observed in overall population.

- Faces Dot-Probe Task (FDOT), Emotional Categorisation Task (ECAT), Emotional Memory Free Recall Task (EREC), Emotional Memory Forced Recognition task (EMEM): on D7 and D55, no effect of treatment was observed in overall population.

\section{Motivation:}

- The mean motivation score showed no relevant differences either between baseline and D56 or between groups in the PPS.

- Regarding gait tasks, no main differences on mean changes from baseline to each visit were observed between treatments except some tendencies in the following criteria:

- A slight lower decrease in walking time for usual pace with the cognitive task from baseline to each post-baseline value was observed with the 3 active treatment groups, and especially with escitalopram $20 \mathrm{mg}$ group as compared to placebo group (at D56: $-3.04 \pm 1.97 \mathrm{~s}$ in the agomelatine $25 \mathrm{mg}$ group, $-3.37 \pm 2.38 \mathrm{~s}$ in the agomelatine $50 \mathrm{mg}$ group, $-2.83 \pm 2.44 \mathrm{~s}$ in the escitalopram $20 \mathrm{mg}$ group, and $-4.99 \pm 5.99 \mathrm{~s}$ in the placebo group).

- A slight greater decrease in walking time for fast walking with the cognitive task from baseline to each post-baseline value was observed with the agomelatine $50 \mathrm{mg}$ group as compared to the other groups, especially escitalopram $20 \mathrm{mg}$ group (at D56: $-0.766 \pm 1.213 \mathrm{~s}$ in the agomelatine $25 \mathrm{mg}$ group, $-1.270 \pm 1.092 \mathrm{~s}$ in the agomelatine $50 \mathrm{mg}$ group, $-0.536 \pm 1.208 \mathrm{~s}$ in the escitalopram $20 \mathrm{mg}$ group, and $-0.837 \pm 1.086 \mathrm{~s}$ in the placebo group).

- Basic probabilistic learning task (Task 1)

- Accuracy :

Regarding treatment effects, on D3 agomelatine $25 \mathrm{mg}$ elicited higher accuracy $(87.6 \pm 7.6 \%)$ than escitalopram $10 \mathrm{mg}(82.2 \pm 9.0 \%)(\mathrm{p}=0.01)$. On D14, agomelatine $50 \mathrm{mg}$ elicited higher accuracy $(91.1 \pm 6.8 \%)$ than placebo $(87.2 \pm 8.3 \%)(\mathrm{p}=0.038)$, agomelatine $25 \mathrm{mg}(86.1 \pm 10.6 \%)(\mathrm{p}=0.012)$, and marginally than escitalopram $20 \mathrm{mg}(87.5 \pm 8.1 \%)(\mathrm{p}=0.057)$. At D56, escitalopram $20 \mathrm{mg}$ elicited higher accuracy $(90.3 \pm 6.2 \%)$ than placebo $(86.4 \pm 8.8 \%)(\mathrm{p}=0.035)$, and marginally than agomelatine $50 \mathrm{mg}(89.7 \pm 4.5 \%)(\mathrm{p}=0.053)$. 


\section{SUMMARY - CONCLUSIONS (Cont'd) \\ PHARMACODYNAMIC RESULTS (Cont'd):}

There was an interaction of treatment with visit and stimulus valence $(F(6,230)=2.24, p=0.041)$. With the positive pair: on D3 agomelatine $25 \mathrm{mg}(91.0 \pm 11.0 \%)$ elicited higher accuracy than escitalopram $10 \mathrm{mg}$ $(82.9 \pm 13.6 \%)(\mathrm{p}=0.013)$. On D14, agomelatine $50 \mathrm{mg}(93.0 \pm 7.0 \%)$ elicited higher accuracy than both escitalopram $20 \mathrm{mg}(87.4 \pm 12.0 \%)(\mathrm{p}=0.025)$ and agomelatine $25 \mathrm{mg}(85.9 \pm 15.1 \%)(\mathrm{p}=0.020)$. On D56, there was a tendency for all three antidepressants to elicit higher accuracy than placebo.

There was an interaction of treatment with task phase and visit $(\mathrm{F}(6,230)=3.37, \mathrm{p}=0.003)$. During the learning phase: on D3 both agomelatine $25 \mathrm{mg}(81.9 \pm 9.4 \%)$ and agomelatine $50 \mathrm{mg}(80.7 \pm 8.4 \%)$ elicited higher accuracy than escitalopram $10 \mathrm{mg}(73.8 \pm 10.7 \%)(\mathrm{p}=0.003$ and $\mathrm{p}=0.007$ respectively). On D14, agomelatine $50 \mathrm{mg}(85.3 \pm 8.9 \%)$ elicited a higher accuracy than escitalopram $20 \mathrm{mg}(80.6 \pm 9.7 \%)$ $(p=0.046)$. On D56, there was no difference between treatment groups. During the exploitation phase: on D3, there was no difference between treatment groups. On D14, agomelatine $50 \mathrm{mg}(96.7 \pm 6.0 \%)$ elicited higher accuracy than agomelatine $25 \mathrm{mg}(91.0 \pm 11.4 \%)(\mathrm{p}=0.016)$. On D56, accuracy with antidepressant treatments was higher than placebo $(90.6 \pm 10.5 \%$ ) (for escitalopram $20 \mathrm{mg}$ : $96.3 \pm 4.6 \%-\mathrm{p}=0.012$; agomelatine $25 \mathrm{mg}: 95.0 \pm 6.5 \%$ - $\mathrm{p}=0.061$; and agomelatine $50 \mathrm{mg}: 96.0 \pm 5.1 \%$ - $\mathrm{p}=0.013$ ).

- Reaction time :

There was a marginal interaction of treatment and valence on reaction time $(\mathrm{F}$ value $=2.54, \mathrm{p}=0.060)$. With the negative pair, reaction time was shorter in the agomelatine $25 \mathrm{mg}$ group $(845.8 \pm 210.9 \mathrm{~ms})$ and in the agomelatine $50 \mathrm{mg}$ group $(852.4 \pm 165.3 \mathrm{~ms})$ than in the placebo group $(931.6 \pm 202.4 \mathrm{~ms})(\mathrm{p}=0.042$ and 0.043 , respectively) and marginally so compared to the escitalopram $20 \mathrm{mg}$ group $(930.5 \pm 220.4 \mathrm{~ms})$ $(\mathrm{p}=0.052$ and 0.055 , respectively $)$.

- Complex probabilistic learning task (Task 2)

- Accuracy:

Regarding treatment effects, there was an interaction of treatment with visit and stimulus valence $(\mathrm{F}(6,234)=2.98, \mathrm{p}<0.01)$. Indeed, with the positive symbol, agomelatine $25 \mathrm{mg}$ elicited higher accuracy $(78 \pm 8.9 \%)$ than all other treatment groups on D3 (placebo: $71 \pm 15 \%-\mathrm{p}=0.02$, escitalopram $10 \mathrm{mg}$ : $71 \pm 16 \%-p=0.03$, and agomelatine $50 \mathrm{mg}: 72 \pm 13 \%-\mathrm{p}=0.039)$. On D14, agomelatine $25 \mathrm{mg}$ elicited higher accuracy $(80 \pm 9.9 \%)$ than escitalopram $20 \mathrm{mg}(73 \pm 51 \%)(\mathrm{p}=0.04)$. There was no significant difference between treatment groups on D56. There was no significant difference across treatment groups with the negative symbol.

- Negative Feedback sensitivity (NFS):

NFS in the agomelatine $25 \mathrm{mg}$ group was significantly lower $(28 \pm 8.6 \%)$ than in the placebo group $(35 \pm 8.8 \%)(\mathrm{p}=0.006)$.

- Risky choices:

As regards treatment, there was an interaction of treatment with visit $(F(6,234)=2.98, p=0.008)$. Indeed, on D3, agomelatine $25 \mathrm{mg}$ elicited more risky actions $(57 \pm 10 \%)$ than placebo $(52 \pm 11 \%)(\mathrm{p}=0.032)$ or escitalopram $10 \mathrm{mg}(52 \pm 11 \%)(\mathrm{p}=0.013)$. On D14, agomelatine $25 \mathrm{mg}$ elicited more risky actions $(53 \pm 10 \%)$ than escitalopram $20 \mathrm{mg}(50 \pm 7.9 \%)(\mathrm{p}=0.036)$, or agomelatine $50 \mathrm{mg}(28 \pm 8.6 \%(\mathrm{p}=0.049)$, but not more than placebo $(53 \pm 9.9 \%)(\mathrm{p}=0.85)$. On D56, no treatment diferences were observed at the exception that agomelatine $50 \mathrm{mg}(48 \pm 12 \%)$ elicited less risky actions than placebo $(\mathrm{p}=0.0056)$. Increase in risky action occurred exclusively on the positive symbol.

- Number of reversals: there was neither main effect of treatment nor any interaction between treatment and visit.

- Reaction time:

There was a main effect of treatment $(F(3,117)=4.88, p=0.003)$ : average reaction time was shorter in the agomelatine $25 \mathrm{mg}$ group $(505.80 \pm 81.1 \mathrm{~ms})$ than in any other treatment groups $(\mathrm{p}=0.002, \mathrm{p}=0.047$ and $\mathrm{p}=0.002$ against placebo $(578.48 \pm 101.3 \mathrm{~ms})$, escitalopram $20 \mathrm{mg}(552.32 \pm 101.6 \mathrm{~ms})$ and agomelatine $50 \mathrm{mg}(588.66 \pm 118.8 \mathrm{~ms})$ groups, respectively). There was an interaction of treatment and valence $\mathrm{F}(3,117)=4.3, \mathrm{p}=0.006)$ : agomelatine $25 \mathrm{mg}$ elicited shorter reaction time than all other treatment groups $(p<0.001, p=0.012, p<0.001$ against placebo, escitalopram $20 \mathrm{mg}$ and agomelatine $50 \mathrm{mg}$ treatment groups respectively with the negative symbol, and $\mathrm{p}<0.001, \mathrm{p}=0.007, \mathrm{p}<0.001$ with the positive symbol). Agomelatine $50 \mathrm{mg}$ group elicited longer reaction time than escitalopram $20 \mathrm{mg}$ group with the negative symbol $(p=0.006)$ but not with the positive symbol $(p=0.18)$. 


\section{SUMMARY - CONCLUSIONS (Cont'd) \\ PHARMACODYNAMIC RESULTS (Cont'd):}

- For motivation and effort task (task 3), treatments affected the following criteria:

- Monetary payoff: payoff was higher in the escitalopram 20mg group (35.9 \pm 1.2 pounds average over visits, all visits pooled) as compared to the placebo group (30.1 \pm 1.4 pounds average over visits) $(\mathrm{p}=0.003)$, agomelatine $50 \mathrm{mg}$ group $(32.2 \pm 1.4$ pounds, average over visits $)(\mathrm{p}=0.051)$. This better performance was stable over time, was mostly driven by the effects of treatment on mean effort duration and on incentives effect on effort duration.

- Mean effort duration was longer in the escitalopram $20 \mathrm{mg}$ group (10.2 $\mathrm{s} \pm 0.6 \mathrm{~seconds}$, average over visits) than in the placebo group (7.6 s \pm 0.6 seconds, average over visits) $(\mathrm{p}=0.002)$ and the agomelatine $50 \mathrm{mg}$ group ( $8.0 \mathrm{~s} \pm 0.6$ seconds, average over visits $)(\mathrm{p}=0.007)$.

- Effect of incentives on effort duration, for which there was a trend toward a treatment effect $(\mathrm{p}=0.079)$ : there was a steeper modulation of effort duration by incentives in the escitalopram $20 \mathrm{mg}$ group $(1.9 \pm 0.3$, average over visits $)$ as compared to placebo $(1.1 \pm 0.2$, average over visits $)$ $(\mathrm{p}=0.023)$.

- The effect of incentives on rest duration was less pronounced in the agomelatine $50 \mathrm{mg}$ group $(-0.15 \pm 0.04)$ than in both agomelatine $25 \mathrm{mg}(\mathrm{p}=0.011)$ and escitalopram $20 \mathrm{mg}(\mathrm{p}=0.043)$ groups.

\section{Sexual acceptability}

The PRSexDQ total score in participants having a sexual activity at baseline and at least at one post-baseline visit, was statistically significantly lower in both agomelatine groups than in the escitalopram $20 \mathrm{mg}$ group at all visits during the treatment period (see Table below) and at the follow-up visit.

Similar results were observed in healthy males subjects, with statistically significant lower total scores in both agomelatine groups than in the escitalopram $20 \mathrm{mg}$ group at D14, D35, D55 and DEND (p-values ranging between $<0.0001$ and 0.017 ). In healthy females, statistically significant lower total score was observed in the agomelatine $25 \mathrm{mg}$ group (at D14 and D35) and agomelatine $50 \mathrm{mg}$ group (at D35) as compared to escitalopram $20 \mathrm{mg}$ group.

The PRSexDQ total score in participants having a sexual activity at baseline and at least at one post-baseline visit, was statistically significantly higher in the escitalopram $20 \mathrm{mg}$ group than in the placebo group at all visits during the treatment period (see Table below) and at the follow-up visit. Similar results were observed in the subgroups of males and females.

Regarding individual item scores during the treatment period, the score for delayed orgasm/ejaculation was slightly greater in the escitalopram $20 \mathrm{mg}$ group than in the agomelatine $25 \mathrm{mg}$ and $50 \mathrm{mg}$ groups at D14 (median 0.5 in the escitalopram $20 \mathrm{mg}$ group versus 0.0 in both agomelatine $25 \mathrm{mg}$ and $50 \mathrm{mg}$ groups) and at D55 (median 1.0 versus 0.0 in both agomelatine groups). The frequency of participants with fair tolerance tended to be greater in the escitalopram $20 \mathrm{mg}$ group than in the other groups $(14.3 \%$ in the escitalopram $20 \mathrm{mg}$ group versus none, $4.0 \%$ and none in the agomelatine $25 \mathrm{mg}, 50 \mathrm{mg}$ and placebo groups, respectively).

No relevant changes were detected in the agomelatine $25 \mathrm{mg}$ and $50 \mathrm{mg}$ groups like in the placebo group for the mean sexual functioning satisfaction (SFS-VAS) score during treatment period. In the escitalopram $20 \mathrm{mg}$ group, the mean (median) SFS-VAS score decreased of $-10.0 \pm 18.2(-5.0) \mathrm{mm}$ at D55: $-3.3 \pm 10.6(-6.0) \mathrm{mm}$ in males and $-15.7 \pm 21.6(-5.0) \mathrm{mm}$ in females. 


\section{SUMMARY - CONCLUSIONS (Cont'd) \\ PHARMACODYNAMIC RESULTS (Cont'd):}

PRSexDQ total score: Comparison between each dose of agomelatine and escitalopram and between escitalopram and placebo by visit in the Per Protocol Set*

\begin{tabular}{|c|c|c|c|c|c|}
\hline & & $\begin{array}{c}\text { Agomelatine } 25 \mathrm{mg} \\
\quad(\mathrm{N}=27)\end{array}$ & $\begin{array}{l}\text { Agomelatine } 50 \mathrm{mg} \\
\quad(\mathrm{N}=\mathbf{2 5})\end{array}$ & $\begin{array}{c}\text { Escitalopram } 20 \mathrm{mg} \\
(\mathrm{N}=\mathbf{2 8})\end{array}$ & $\begin{array}{l}\text { Placebo } \\
(\mathbf{N}=30)\end{array}$ \\
\hline \multirow[t]{2}{*}{ Baseline } & $\mathrm{n}$ & 27 & 25 & 28 & 30 \\
\hline & Mean \pm SD & $0.4 \pm 0.8$ & $0.3 \pm 0.8$ & $0.8 \pm 2.2$ & $0.3 \pm 0.6$ \\
\hline \multirow[t]{6}{*}{ D14 } & $\mathrm{n}$ & 23 & 22 & 24 & 29 \\
\hline & Mean \pm SD & $0.2 \pm 0.4$ & $0.9 \pm 2.1$ & $3.2 \pm 3.3$ & $0.2 \pm 0.5$ \\
\hline & & \multicolumn{2}{|c|}{ escitalopram versus agomelatine } & \multicolumn{2}{|c|}{ escitalopram versus placebo } \\
\hline & $\mathrm{E}(\mathrm{SE})(1)$ & $2.8(0.5)$ & $2.0(0.5)$ & \multicolumn{2}{|l|}{$2.7(0.5)$} \\
\hline & $95 \%$ CI (2) & {$[1.7 ; 3.8]$} & {$[0.9 ; 3.0]$} & \multicolumn{2}{|l|}{$[1.7 ; 3.7]$} \\
\hline & p-value (3) & $<0.0001$ & 0.0004 & \multicolumn{2}{|l|}{$<0.0001$} \\
\hline \multirow[t]{6}{*}{ D35 } & $\mathrm{n}$ & 25 & 25 & 26 & 29 \\
\hline & Mean \pm SD & $0.7 \pm 1.3$ & $0.7 \pm 1.8$ & $3.5 \pm 3.2$ & $0.5 \pm 1.2$ \\
\hline & & \multicolumn{2}{|c|}{ escitalopram versus agomelatine } & \multicolumn{2}{|c|}{ escitalopram versus placebo } \\
\hline & $\mathrm{E}(\mathrm{SE})(1)$ & $2.7(0.6)$ & $2.6(0.6)$ & \multicolumn{2}{|l|}{$2.8(0.5)$} \\
\hline & $95 \% \mathrm{CI}(2)$ & {$[1.6 ; 3.8]$} & {$[1.5 ; 3.8]$} & \multicolumn{2}{|l|}{$[1.7 ; 3.9]$} \\
\hline & p-value (3) & $<0.0001$ & $<0.0001$ & \multicolumn{2}{|l|}{$<0.0001$} \\
\hline \multirow[t]{6}{*}{ D55 } & $\mathrm{n}$ & 24 & 24 & 25 & 28 \\
\hline & Mean \pm SD & $1.1 \pm 2.0$ & $0.8 \pm 1.6$ & $3.0 \pm 3.1$ & $0.4 \pm 0.8$ \\
\hline & & \multicolumn{2}{|c|}{ escitalopram versus agomelatine } & \multicolumn{2}{|c|}{ escitalopram versus placebo } \\
\hline & $\mathrm{E}(\mathrm{SE})(1)$ & $1.9(0.6)$ & $2.1(0.6)$ & \multicolumn{2}{|l|}{$2.5(0.6)$} \\
\hline & $95 \%$ CI (2) & {$[0.7 ; 3.0]$} & {$[0.9 ; 3.2]$} & \multicolumn{2}{|l|}{$[1.4 ; 3.6]$} \\
\hline & p-value (3) & 0.0016 & 0.0005 & \multicolumn{2}{|l|}{$<0.0001$} \\
\hline
\end{tabular}

* In participants with sexual activity at baseline and at least at one post-baseline visit until D55

Analysis of variance model on factor treatment with centre, gender and baseline as covariates (fixed effect)

(1) Estimate (standard error) of the difference between adjusted group means: escitalopram $20 \mathrm{mg}$ minus agomelatine $25 \mathrm{mg}$ or escitalopram $20 \mathrm{mg}$ minus agomelatine $50 \mathrm{mg}$ or escitalopram $20 \mathrm{mg}$ minus placebo

(2) $95 \%$ confidence interval of the estimate

(3) p-value for the difference between adjusted group means

Subjective scales (HAD and STAI STATE), SASS scale and Physical and cognitive functioning In the PPS no changes were observed on these criteria during the study. 


\begin{tabular}{|c|c|c|c|c|c|}
\hline \multicolumn{6}{|l|}{$\begin{array}{l}\text { SUMMARY - CONCLUSIONS (Cont'd) } \\
\text { SAFETY RESULTS: }\end{array}$} \\
\hline \multicolumn{6}{|l|}{ Emergent adverse events } \\
\hline \multicolumn{6}{|c|}{ Overall summary of emergent adverse events on treatment in the Safety Set } \\
\hline & & $\begin{array}{c}\text { Agomelatine } \\
25 \mathrm{mg} \\
(\mathrm{N}=\mathbf{3 3})\end{array}$ & $\begin{array}{c}\text { Agomelatine } \\
50 \mathrm{mg} \\
(\mathbf{N}=\mathbf{3 2})\end{array}$ & $\begin{array}{c}\text { Escitalopram } \\
20 \mathrm{mg} \\
(\mathrm{N}=\mathbf{3 6})\end{array}$ & $\begin{array}{r}\text { Placebo } \\
(\mathbf{N}=32)\end{array}$ \\
\hline \multicolumn{6}{|l|}{ Participants having reported } \\
\hline At least one EAE & $\mathrm{n}(\%)$ & $27(81.8)$ & $24(75.0)$ & $31(86.1)$ & $27(84.4)$ \\
\hline At least one treatment-related EAE & $\mathrm{n}(\%)$ & $12(36.4)$ & $10(31.3)$ & $22(61.1)$ & $12(37.5)$ \\
\hline At least one severe EAE & $\mathrm{n}(\%)$ & $2(6.1)$ & $1(3.1)$ & $1(0.9)$ & $3(3.6)$ \\
\hline At least one EAE leading to treatment discontinuation & $\mathrm{n}(\%)$ & $2(6.1)$ & - & $2(5.6)$ & - \\
\hline At least one serious EAE & $\mathrm{n}(\%)$ & $2(6.1)$ & - & - & - \\
\hline At least one treatment-related serious EAE & $\mathrm{n}(\%)$ & $1(3.0)$ & - & - & - \\
\hline Treatment discontinuation due to serious EAE & $\mathrm{n}(\%)$ & $2(6.1)$ & - & - & - \\
\hline
\end{tabular}

$n$ : number of volunteers affected

During the treatment period in the Safety Set, the percentage of participants with at least one emergent adverse event showed no relevant difference between treatment groups (see Table above).

The most frequently affected system organ classes (in at least $15 \%$ of participants) on agomelatine during the treatment period in the Safety Set were nervous system disorders, infections and infestations, gastrointestinal disorders, psychiatric disorders and general disorders and administration site conditions. It was also the case in the escitalopram and the placebo groups except for the last one.

Infections and infestations were more common in the agomelatine $25 \mathrm{mg}$ group (45.5\% of participants affected) than in the placebo group (37.5\%), and similarly reported in the agomelatine $50 \mathrm{mg}$, escitalopram $20 \mathrm{mg}$ groups and placebo group $(34.4 \%, 30.6 \%$ and $37.5 \%$, respectively).

The percentages of participants with nervous system disorders, gastrointestinal disorders and psychiatric disorders were similar to or lower in the agomelatine $25 \mathrm{mg}$ group $(42.4 \%, 18.2 \%$ and $18.2 \%$, respectively), and the agomelatine $50 \mathrm{mg}$ group $(40.6 \%, 15.6 \%$ and $15.6 \%$, respectively) than in the placebo group $(40.6 \%, 25.0 \%$ and $21.9 \%$, respectively). Inversely, they were greater (at least 2 more participants) in the escitalopram $20 \mathrm{mg}$ group $(61.1 \%, 36.1 \%$ and $30.6 \%$, respectively) than in the placebo group.

The percentage of participants with general disorders and administration site conditions was higher in the agomelatine $25 \mathrm{mg}$ group (15.2\%) and the escitalopram $20 \mathrm{mg}$ group (13.9\%) than in the placebo group $(9.4 \%)$.

During the treatment period, the most frequent emergent adverse events on agomelatine (reported in at least 5 participants in any agomelatine group) were:

- Headache, reported in $18.2 \%$ of patients in the agomelatine $25 \mathrm{mg}$ group, $25.0 \%$ in the agomelatine $50 \mathrm{mg}$ group, $36.1 \%$ in the escitalopram $20 \mathrm{mg}$ group, and $21.9 \%$ in the placebo group.

- Somnolence: $21.2 \%, 12.5 \%, 13.9 \%$ and $6.3 \%$, repectively.

- Upper respiratory tract infection: $18.2 \%, 9.4 \%, 11.1 \%$, and $6.3 \%$.

- Nasopharyngitis: $15.2 \%, 6.3 \%, 16.7 \%$, and $25.0 \%$.

Few participants experienced severe emergent adverse events during the treatment period: 2 participants in the agomelatine $25 \mathrm{mg}$ group (diarrhoea and nightmare in one subject and ovarian cyst torsion in the other one), 1 participant in the agomelatine $50 \mathrm{mg}$ group (upper respiratory tract infection), 1 in the escitalopram $20 \mathrm{mg}$ groups (headache), and 3 participants in the placebo group (dry mouth, abnormal dreams and ejaculation failure, respectively).

In both agomelatine groups, the most common system organ classes with treatment-related emergent adverse events were nervous system disorders and psychiatric disorders. Both system organ classes were similarly or less affected in the agomelatine $25 \mathrm{mg}$ and $50 \mathrm{mg}$ groups than in the placebo group except for nervous system disorders in the agomelatine $25 \mathrm{mg}$ group. Both frequencies in the escitalopram were higher than in the placebo group and than in the agomelatine $25 \mathrm{mg}$ and $50 \mathrm{mg}$ groups. 


\section{SUMMARY - CONCLUSIONS (Cont'd) \\ SAFETY RESULTS (Cont'd): \\ No death was reported during the study. \\ Two participants, both in the agomelatine $25 \mathrm{mg}$ group (6.1\%), had emergent serious adverse events. One participant had two serious adverse events considered as treatment-related by the investigator (ALAT and ASAT increased, see below "liver acceptability"). The other participant experienced not treatment-related severe ovarian cyst torsion. For both participants, emergent serious adverse events led to study drug withdrawal and resolved.}

Two participants, both in the escitalopram $20 \mathrm{mg}$ group (5.6\%), experienced 7 non-serious emergent adverse events leading to study treatment discontinuation. Five events (agitation and tremor in one participant and anxiety, dizziness and restless legs in the other participant) were considered as treatment-related by the investigator.

\section{Laboratory tests}

In the Safety Set, neither clinically relevant changes over time nor differences between groups were detected for biochemical and haematological parameters during the study except for the mean CPK increase in the escitalopram $20 \mathrm{mg}$ group $(55.1 \pm 166.1 \mathrm{IU} / \mathrm{L}$ versus $4.1 \pm 69.8 \mathrm{IU} / \mathrm{L}$ in the placebo group). The median CPK was $17.0 \mathrm{IU} / \mathrm{L}$ and the Q3 was $66 \mathrm{IU} / \mathrm{L}(\max 691 \mathrm{IU} / \mathrm{L})$ in the escitalopram $20 \mathrm{mg}$ group at study end visit, and no PCSA value of CPK was reported.

Few emergent PCSA biochemical values were reported, all in the escitalopram $20 \mathrm{mg}$ group (3 PCSA for urea and 1 for triglycerides) and none was considered as clinically significant by the investigator.

There was no emergent PCSA haematological value during the treatment period.

\section{Liver acceptability}

As regards liver acceptability, emergent PCSA values of ALAT or ASAT were reported in 2 participants of the agomelatine $25 \mathrm{mg}$ group at D14 visit.

PCSA value of ALAT (3.5 ULN) was associated with out-of-reference-range value of ASAT (2.2 ULN) in 1 participant and both abnormal values were reported as serious related emergent adverse events. The participant recovered after study drug withdrawal (56 days after the last intake values decreased to $0.5 \mathrm{ULN}$ for ALAT and $0.8 \mathrm{ULN}$ for ASAT). This case was reviewed by an independent expert scientific committee who considered these increases being due to a recent CMV infection instead of the studied drug. The other participant reported high PCSA value for ASAT (3.0 ULN) associated with ALAT value above the upper limit of reference range (1.1 ULN). No adverse event was reported. At retest (two days later on treatment), values for ASAT and ALAT returned within the normal range.

\section{Vital signs and BMI}

In the Safety Set, neither clinically relevant mean changes over the treatment period nor differences between groups were detected for supine blood pressures and heart rate.

In the Safety Set, there were no clinically relevant differences in mean weight or BMI between baseline and follow-up visit in any group, nor relevant differences between the treatment groups.

\section{BDNF and VGEF results}

\section{BDNF}

In the PPS, the median level of serum BDNF was slightly higher at last post-baseline assessment than at baseline in the agomelatine $25 \mathrm{mg}$ (from $13702.4 \mathrm{pg} / \mathrm{ml}$ at baseline to $15751.9 \mathrm{pg} / \mathrm{ml}$ at the last post-baseline assessment), agomelatine $50 \mathrm{mg}$ (from $11727.4 \mathrm{pg} / \mathrm{ml}$ to $13795.6 \mathrm{pg} / \mathrm{ml}$ ) and placebo (from $14914.7 \mathrm{pg} / \mathrm{ml}$ to $15445.5 \mathrm{pg} / \mathrm{ml}$ ) groups, with a greater increase on agomelatine than on placebo. In the escitalopram $20 \mathrm{mg}$ group, the median level was lower at last post-baseline assessment $(13502.0 \mathrm{pg} / \mathrm{ml})$ than at baseline $(14052.3 \mathrm{pg} / \mathrm{ml})$.

As regards plasma level, the median BDNF was higher at the last post-baseline assessment on treatment than at baseline in the three active treatment groups, and inversely in the placebo group. This treatment effet was mainly observed in the agomelatine $25 \mathrm{mg}$ group (from $1136.1 \mathrm{pg} / \mathrm{ml}$ at baseline to $2143.6 \mathrm{pg} / \mathrm{ml}$ at the last post-baseline assessment) and escitalopram $20 \mathrm{mg}$ group (from $1044.2 \mathrm{pg} / \mathrm{ml}$ to $1575.1 \mathrm{pg} / \mathrm{ml}$ ). 


\begin{tabular}{|c|c|c|c|c|c|}
\hline \multicolumn{6}{|c|}{$\begin{array}{l}\text { SUMMARY - CONCLUSIONS (Cont'd) } \\
\text { SAFETY RESULTS (Cont'd): }\end{array}$} \\
\hline \multicolumn{6}{|c|}{$\begin{array}{l}\text { VEGF } \\
\text { In the PPS, the median level of serum VEGF was slightly higher at last post-baseline assessment that } \\
\text { baseline in the agomelatine } 50 \mathrm{mg} \text { group (from } 342.5 \mathrm{pg} / \mathrm{ml} \text { at baseline to } 423.0 \mathrm{pg} / \mathrm{ml} \text { at the last post-base } \\
\text { assessment) and placebo group (from } 507.3 \mathrm{pg} / \mathrm{ml} \text { to } 568.1 \mathrm{pg} / \mathrm{ml} \text { ); and was smaller in the agomelatine } 25 \\
\text { (from } 503.3 \mathrm{pg} / \mathrm{ml} \text { to } 453.7 \mathrm{pg} / \mathrm{ml} \text { ) and escitalopram } 20 \mathrm{mg} \text { (from } 525.6 \mathrm{pg} / \mathrm{ml} \text { to } 502.1 \mathrm{pg} / \mathrm{ml} \text { ) groups. } \\
\text { As regards plasma level, the median VEGF was slightly smaller at last post-baseline assessment that } \\
\text { baseline in all groups without relevant differences between them. }\end{array}$} \\
\hline \multicolumn{6}{|c|}{ Pharmacokinetic results } \\
\hline \multicolumn{6}{|c|}{ Descriptive statistics of agomelatine pharmacokinetic parameters in plasma by dose } \\
\hline $\begin{array}{l}\text { Agomelatine } \\
\text { dose (mg) }\end{array}$ & $\mathbf{N}$ & $\begin{aligned} \mathbf{A U C}_{24}{ }^{(1)} \\
\text { (ng.h/mL) }\end{aligned}$ & $\begin{array}{c}\mathbf{C}_{\max }{ }^{(1)} \\
(\mathrm{ng} / \mathrm{mL})\end{array}$ & $\underset{\max }{\mathbf{t}_{\max }}$ & $\mathbf{t}_{1 / 2} \mathrm{z}^{(1)}$ \\
\hline 25 & $31^{(3)}$ & $\begin{array}{l}19.6 \pm 20.2 \\
\quad(13.6)\end{array}$ & $\begin{array}{l}12.8 \pm 15.7 \\
\quad(7.55)\end{array}$ & $\begin{array}{c}1.25 \\
(0.20-4.0)\end{array}$ & $\begin{array}{l}2.07 \pm 0.166 \\
(2.04)\end{array}$ \\
\hline 50 & 32 & $\begin{array}{l}65.5 \pm 113 \\
\quad(32.2)\end{array}$ & $\begin{array}{l}27.4 \pm 42.6 \\
\quad(10.0)\end{array}$ & $\begin{array}{c}1.25 \\
(0.10-5.0)\end{array}$ & $\begin{array}{l}2.13 \pm 0.262 \\
\quad(2.06)\end{array}$ \\
\hline $\begin{array}{l}\text { (1) }: \text { mean } \pm S D(\text { me } \\
\text { (2): median (min-mo } \\
\left({ }^{(3)} \text { : One subject fro }\right.\end{array}$ & & $\begin{array}{l}N \text { : number o. } \\
\text { did not under }\end{array}$ & & & \\
\hline
\end{tabular}

The mean and median plasma pharmacokinetic parameters based on the simulated plasma concentrations showed that similar $t_{\max }$ and $t_{1 / 2, z}$ values were obtained for 25 and $50 \mathrm{mg}$ doses, and the $\mathrm{AUC}_{24}$ and $\mathrm{C}_{\max }$ increased approximately proportionally with the dose between 25 and $50 \mathrm{mg}$. At $25 \mathrm{mg}$, the median $\mathrm{AUC}_{24}$ and $\mathrm{C}_{\max }$ values in this study $\left(13.6 \mathrm{ng} . \mathrm{h} / \mathrm{mL}\right.$ and $7.55 \mathrm{ng} / \mathrm{mL}$, respectively) were similar to the median $\mathrm{AUC}_{24}$ and $\mathrm{C}_{\max }$ values in the previous combined population pharmacokinetic analysis $(13 \mathrm{ng} . \mathrm{h} / \mathrm{mL}$ and $5.3 \mathrm{ng} / \mathrm{mL}$, respectively). At $50 \mathrm{mg}$, the median $\mathrm{AUC}_{24}$ in this study $(32.2 \mathrm{ng} . \mathrm{h} / \mathrm{mL})$ was 1.9 -fold lower than the $\mathrm{AUC}_{24}$ value in the combined population pharmacokinetic analysis $(60 \mathrm{ng} \cdot \mathrm{h} / \mathrm{mL})$ and the $\mathrm{C}_{\max }$ value in this study $(10.0 \mathrm{ng} / \mathrm{mL})$ was 2.5 -fold lower than the $C_{\max }$ value in the combined population pharmacokinetic analysis $(25 \mathrm{ng} / \mathrm{mL})$. However, these observations were within the known variability of agomelatine. 


\section{CONCLUSION}

This multicentric, randomised, double-blind, placebo-controlled study conducted in healthy volunteers showed that no emotional blunting was induced by agomelatine $(25 \mathrm{mg}$ or $50 \mathrm{mg})$, escitalopram or placebo during the study. Also there was no statistically significant difference between treatments groups.

Results obtained with the Emotional Test Battery failed to demonstrate main treatment effects in the overall population except for the facial expression recognition task (FERT) where, after 7 days treatment, a decreased bias towards labeling faces as disgust and as surprise was observed with escitalopram $10 \mathrm{mg}$ as compared to placebo, whereas a bias towards misclassifying faces as happy was observed with agomelatine $25 \mathrm{mg}$ in comparison to placebo.

As regards gait tasks, descriptive statistics showed no beneficial effects of treatments, except a slightly higher decrease in walking time for fast walking with the cognitive task in the agomelatine $50 \mathrm{mg}$ group as compared to the other groups, especially to escitalopram $20 \mathrm{mg}$ group.

As regards basic probabilistic learning task, an early beneficial effect on accuracy was observed with agomelatine $25 \mathrm{mg}$ (D3) and agomelatine $50 \mathrm{mg}$ (D14) compared to escitalopram 10-20 mg, respectively on D3 and D14. This effect was primarily driven by an increased sensitivity to positive, rewarding stimuli, and arose in the learning phase of the task.

As regards complex probabilistic learning task, an early beneficial effect on accuracy was observed with agomelatine $25 \mathrm{mg}$ compared to escitalopram 10-20 mg (D3 and D14) and placebo (D3), which was specific to positive stimuli. This was achieved with an increased ability to disregard misleading negative feedback with agomelatine $25 \mathrm{mg}$ while at the same time improving reaction time. This earlier beneficial cognitive effect of agomelatine $25 \mathrm{mg}$ may allow patients to quickly relearn positive associations and help them overcome a negative depressed mindset.

Regarding the motivation and effort task, escitalopram 10-20 $\mathrm{mg}$ led to a better payoff in the task by both increasing the time spent on effort and by spending longer effort for high-value versus low-value trials. Agomelatine $25 \mathrm{mg}$ tended to have similar effects to escitalopram $20 \mathrm{mg}$, but to a lesser extent, whereas agomelatine $50 \mathrm{mg}$ had effects more similar to placebo.

As regards sexual acceptability (PRSexDQ), this study confirmed the statistically significantly better acceptability of agomelatine $25 \mathrm{mg}$ and $50 \mathrm{mg}$ than the SSRI escitalopram $20 \mathrm{mg}$, in both males and females. This agomelatine effect as compared to escitalopram effect was higher in men.

No relevant effects of treatments were observed on plasma and serum BDNF or VEGF levels with the exception of an increase between baseline and last post-baseline assessments of plasma BDNF level after agomelatine $25 \mathrm{mg}$ and escitalopram $20 \mathrm{mg}$ treatments.

The safety profile of agomelatine $25-50 \mathrm{mg}$ reported in this study was in line with the known safety profile of agomelatine. Two cases of reversible transaminases increases (maximum values $3.5 \mathrm{ULN}$ and $3 \mathrm{ULN}$ ) were reported in the agomelatine $25 \mathrm{mg}$ dose regimen. The safety profile of escitalopram $20 \mathrm{mg} / \mathrm{d}$ followed its SmPC.

Date of the report: 24 July 2014

Version of the report: Final version 